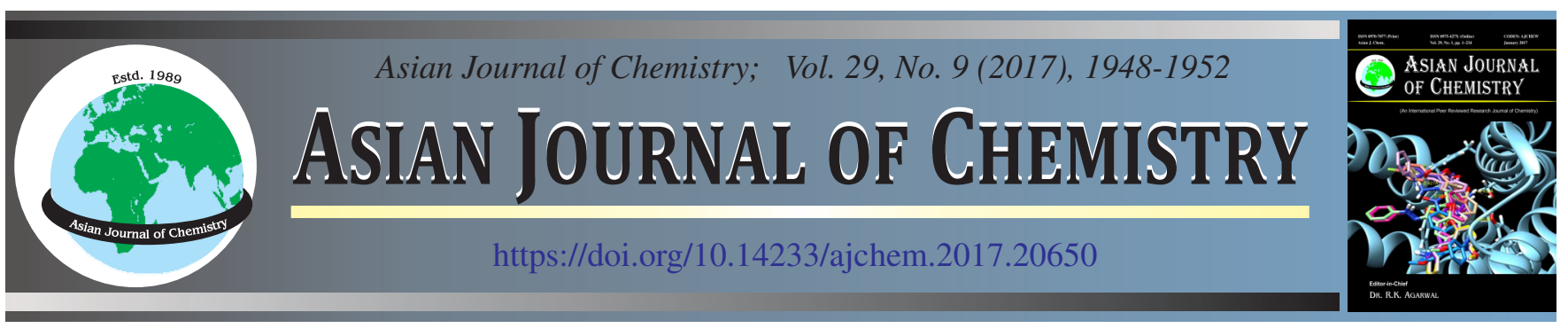

\title{
Comparative Studies on Tributylammonium Chlorochromate Oxidation of Pentaammine Cobalt(III) Complexes of $\alpha$-Hydroxy Acids Catalyzed by Benzalkonium Chloride
}

\author{
R. DAYANANDhAN ${ }^{1,2, *}$ and K. Subramani ${ }^{3}$
}

${ }^{1}$ Research and Development Center, Bharathiar University, Coimbatore-641 046, India

${ }^{2}$ Department of Chemistry, Sri Vidya Mandir Arts \& Science College,Uthangarai-636 902, India

${ }^{3}$ Department of Chemistry, Islamiah College, Vaniyambadi-635 752, India

*Corresponding author: E-mail: dayachemistry@gmail.com

Received: 13 March 2017;

Accepted: 30 May 2017;

Published online: 15 July 2017;

AJC-18471

A benzalkonium chloride (BKC) catalyzed oxidation of pentaammine cobalt(III) complexes of both bound and unbound $\alpha$-hydroxy acids
by tributylammonium chlorochromate (TriBACC) has been studied. Perchloric acid is adapted as a medium and the oxidative kinetics was
contrived spectrophotometrically at room temperature. Rate of TriBACC oxidation is carried out at pseudo-first order conditions and rate
constant was calculated. Absence of salt effect is observed on increasing $\mathrm{NaClO}_{4}$ concentration. Abatement in $\mathrm{UV}$-visible absorbance at
$503 \mathrm{~nm}$ for $\mathrm{Co}$ (III) complex confirms to nearly $100 \%$ of initial absorbance. The complex $\left[\left(\mathrm{NH}_{3}\right)_{5} \mathrm{Co}(\mathrm{III})-\mathrm{L}\right]^{2+}$ shows inner sphere mechanism
and induced electron transfer reaction yields $100 \% \mathrm{Co}$ (II). The product formed in this oxidation was analyzed and polymerization test
was carried out. Comparative study of rate of TriBACC oxidation in presence of benzalkonium chloride is listed out.

Keywords: Cobalt(III) complexes, Hydroxy acids, Benzalkonium chloride, Oxidation, Tritutylammonium chlorochromate.

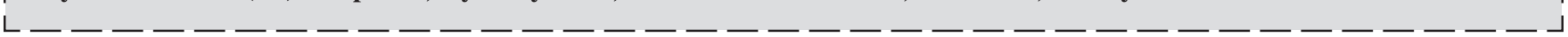

\section{INTRODUCTION}

The oxidation of $\alpha$-hydroxy acids such as lactic acid, mandelic acid and their pentaammine cobalt(III) complexes using tributylammonium chlorochromate (TriBACC) has been carried out in presence of a benzalkonium chloride (BKC). Less work has been done on TriBACC oxidant with cobalt(III) complex. TriBACC is easily soluble in water, Inexpensive, stable, non-hygroscopic and easy to prepare in good yield. The reaction between [TriBACC] and [substrate] exhibits total second order kinetics and first order with respect to concentration of each oxidant and substrate. The oxidation of $\mathrm{Co}(\mathrm{III})-$ L complex shows induced electron transfer reaction with the external oxidant. It is proved that $\mathrm{Cr}(\mathrm{VI})$ reagents is the best for the oxidation of most organic functional groups [1-3]. In recent years, more achievement were made using new $\mathrm{Cr}(\mathrm{VI})$ reagents such as tripropylammonium fluorochromate [4], pyridinium fluorochromate [5], tetrabutylammonium chlorochromate [6] and tetraethyl ammonium chlorochromate [7] etc., have been attempted to determine the kinetic and mechanistic route of various organic compounds [8-16].

Tributylammonium chlorochromate oxidant was prepared serenely and workup procedure, short reaction time, excellent yield and it is new, stable and effective conditions shows the superiority of this reagent.

\section{EXPERIMENTAL}

Chemicals purchased are of Analytical grade (Merck, India). Perchloric acid was standardized with standard sodium carbonate solution with methyl orange as indicator.

Pentaammine cobalt(III) complexes of bound $\alpha$-hydroxy acids were prepared as their perchlorates by the reported procedure of Taube and Gould [17].

$\left[\left(\mathrm{NH}_{3}\right)_{5} \mathrm{Co}(\mathrm{III})-\mathrm{OOC}-\mathrm{CH}(\mathrm{OH})-\mathrm{CH}_{3}\right]\left(\mathrm{ClO}_{4}\right)_{2}$-pentaammine cobalt(III) lactato complex

$\left[\left(\mathrm{NH}_{3}\right)_{5} \mathrm{Co}(\mathrm{III})-\mathrm{OOC}-\mathrm{CH}(\mathrm{OH})-\mathrm{C}_{6} \mathrm{H}_{5}\right]\left(\mathrm{ClO}_{4}\right)_{2}$-pentaammine cobalt(III) mandelato complex

Tributylammonium chlorochromate (TriBACC) was prepared by the reported procedure [18]. UV/visible, IR and ${ }^{1} \mathrm{H}$ NMR data were all consistent with the TriBACC structure. Purity of the oxidant is verified by iodimetric procedure.

Kinetic methods and rate measurements: All the reactions were conducted under visible region. Elico UV-visible (FL244) spectrophotometer has been employed. Total volume of the cell is kept to $2.5 \mathrm{~mL}$ in every kinetic run. Ionic strength in each kinetic run kept constant using $\mathrm{HClO}_{4}-\mathrm{NaClO}_{4}$ mixtures. Decrease in absorbance is observed from $\lambda=375 \mathrm{~nm}$ for TriBACC oxidation of unbound $\alpha$-hydroxy acids by keeping substrate concentration 10 times excess than oxidant. Similarly decrease in absorbance from $\lambda=503 \mathrm{~nm}$ for $\mathrm{Co}$ (III) bound 
complex, here oxidant concentration is 10 times excess than the complex. Each reaction is done in pseudo-first order conditions and rate constant is calculated from slope of the graph and the first order rate equation is calculated by the method of least square.

$$
\mathrm{k}_{1}=(2.303 / \mathrm{t}) \times \log [\mathrm{a} /(\mathrm{a}-\mathrm{x})]
$$

$\mathrm{k}_{1}=2.303 \times$ slope, where $\mathrm{k}_{1}$ is the pseudo-first order rate constant, ' $\mathrm{t}$ ' is the time in sec. $\mathrm{k}_{2}$ is the second order rate constant.

\section{RESULTS AND DISCUSSION}

The kinetic oxidation of lactic acid, mandelic acid and their pentaammine cobalt(III) complexes by TriBACC at room temperature $30 \pm 0.2{ }^{\circ} \mathrm{C}$ in perchloric acid medium in presence of benzalkonium chlorides is attempted. Temperature is kept constant for every kinetic runs.

Rate dependence on TriBACC concentration: The rate dependence of TriBACC oxidation of both bound and unbound $\alpha$-hydroxy acids has been adhered under pseudo first order condition in presence of benzalkonium chloride by keeping excess of the hydroxy acid concentration than the oxidant. Rate constant $\left(\mathrm{k}_{\text {calc }}\right)$ is calculated by integrated first order rate equation. Graph of $4+\operatorname{logs}(\mathrm{a}-\mathrm{x})$ versus time was linear and the rate constant $\left(\mathrm{k}_{1}\right)$ is calculated from the slope which was agreed with calculated value of rate constant which shows the first order rate dependence of [TriBACC]. Every kinetic run was reproducible within the range $\pm 2 \%$. On changing the normality of TriBACC from $1.0 \times 10^{-2}$ to $4.0 \times 10^{-2} \mathrm{~mol} \mathrm{dm}^{-3}$ and keeping concentrations of substrate, benzalkonium chloride, perchloric acid fixed (Table-1 and Fig. 1). The value of $\mathrm{k}_{1}$ is independent of initial concentration of TriBACC. The rate is expressed as:

$$
-\mathrm{d}[\mathrm{TriBACC}] / \mathrm{dt}=\mathrm{k}_{1}[\text { TriBACC }]
$$

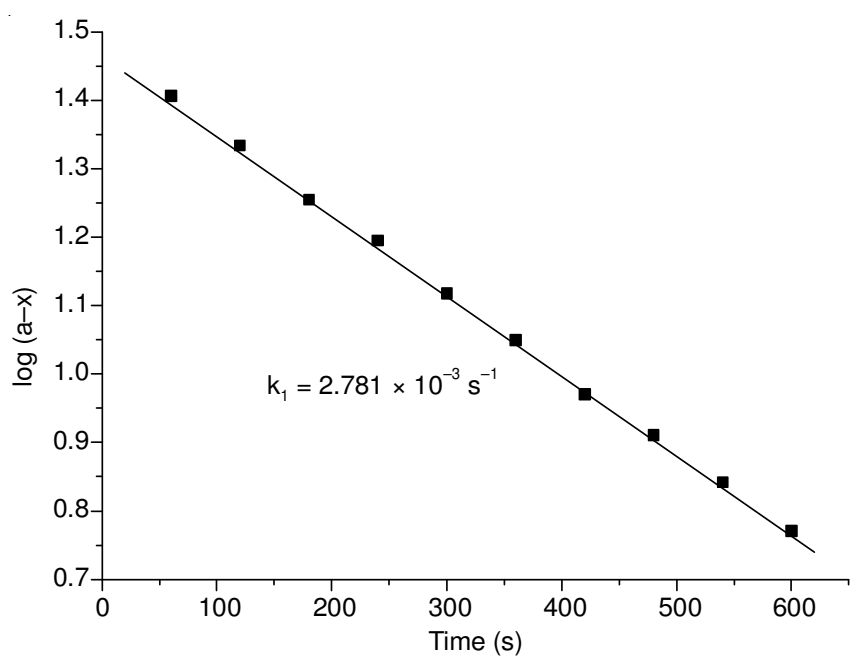

Fig. 1. Pseudo first order plot of $\log (\mathrm{a}-\mathrm{x})$ versus time rate dependence for TriBACC

Rate dependence on hydroxy acid concentration: On increasing the concentration of hydroxy acids bound and unbound at $1.0 \times 10^{-1}$ to $4.0 \times 10^{-1} \mathrm{~mol} \mathrm{dm}^{-3}$ the rate increases proportionately. The plot of $\left[4+\log \mathrm{k}_{1}\right]$ versus $2+\log$ [hydroxy acids] is a linear with slope nearness to unity is the first order
TABLE-1

EFFECT OF VARYING CONCENTRATION OF TriBACC

\begin{tabular}{ccc}
\hline Time $(\mathrm{s})$ & $(\mathrm{a}-\mathrm{x})\left(\mathrm{mol} \mathrm{dm}^{-3}\right)$ & $10^{3} \mathrm{k}_{1}\left(\mathrm{~s}^{-1}\right)$ \\
\hline 60 & 2.550 & 2.79 \\
120 & 2.160 & 2.78 \\
180 & 1.800 & 2.86 \\
240 & 1.570 & 2.73 \\
300 & 1.310 & 2.77 \\
360 & 1.120 & 2.75 \\
420 & 0.934 & 2.79 \\
480 & 0.814 & 2.73 \\
540 & 0.696 & 2.72 \\
600 & 0.590 & 2.72 \\
\multicolumn{3}{c}{} \\
\hline
\end{tabular}

rate dependence of hydroxy acids. The rate is compared in

\begin{tabular}{|c|c|c|}
\hline \multicolumn{3}{|c|}{$\begin{array}{c}\text { TABLE-2 } \\
\text { EFFECT OF RATE ON VARYING } \\
\text { HYDROXY ACIDS CONCENTRATION }\end{array}$} \\
\hline \multirow{2}{*}{ [Hydroxy acids] } & \multicolumn{2}{|c|}{ Benzalkonium chloride } \\
\hline & $10^{4} \mathrm{k}_{1}\left(\mathrm{~s}^{-1}\right)$ & $10^{2} \mathrm{k}_{2}\left(\mathrm{~mol}^{-1} \mathrm{dm}^{3} \mathrm{~s}^{-1}\right)$ \\
\hline \multicolumn{3}{|l|}{ Lactic acid [LA] } \\
\hline 0.1 & 2.85 & 2.85 \\
\hline 0.2 & 5.66 & 2.83 \\
\hline 0.3 & 8.50 & 2.83 \\
\hline 0.4 & 11.3 & 2.82 \\
\hline \multicolumn{3}{|l|}{ Mandelic acid [MA] } \\
\hline 0.1 & 2.44 & 2.44 \\
\hline 0.2 & 4.90 & 2.45 \\
\hline 0.3 & 7.29 & 2.43 \\
\hline 0.4 & 9.74 & 2.44 \\
\hline \multicolumn{3}{|l|}{ Lactato complex } \\
\hline 0.1 & 0.88 & 0.88 \\
\hline 0.2 & 1.75 & 0.87 \\
\hline 0.3 & 2.64 & 0.88 \\
\hline 0.4 & 3.52 & 0.88 \\
\hline \multicolumn{3}{|l|}{ Mandelato complex } \\
\hline 0.1 & 0.67 & 0.67 \\
\hline 0.2 & 1.33 & 0.66 \\
\hline 0.3 & 1.99 & 0.66 \\
\hline 0.4 & 2.66 & 0.66 \\
\hline
\end{tabular}
presence of benzalkonium chloride (Table-2 and Fig. 2).

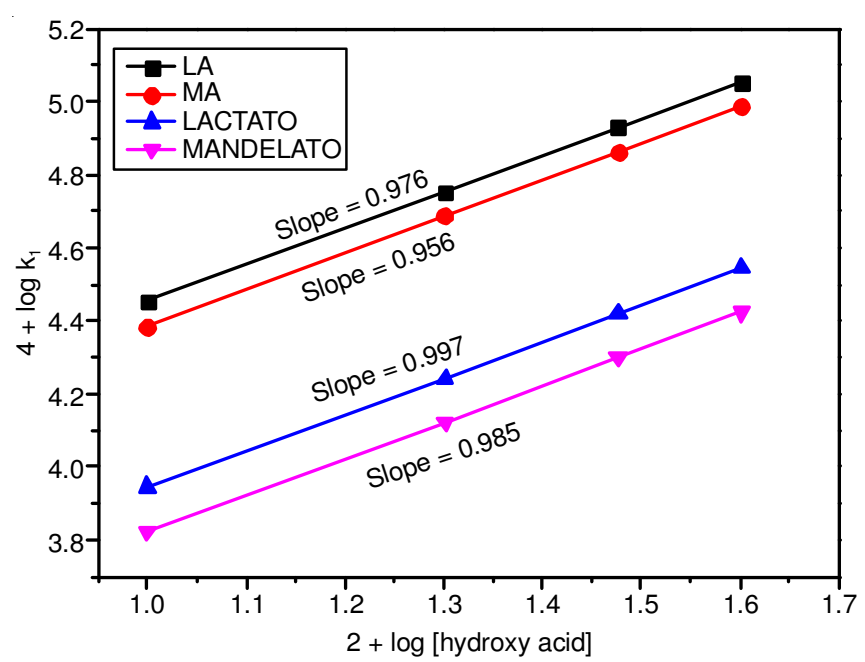

Fig. 2. Rate dependence of hydroxy acid in presence of benzalkonium chloride 
Comparison of rate of TriBACC oxidation is given in presence of benzalkonium chloride as follows:

\section{Lactic acid > Mandelic acid > Lactato $>$ Mandelato}

Rate dependence on perchloric acid concentration: Kinetic investigations were attempted on varying the perchloric acid normality at $1.0 \times 10^{-2}$ to $4.0 \times 10^{-2} \mathrm{~mol} \mathrm{dm}^{-3}$ and by keeping all other constituents constants in each kinetic run, the value of $\mathrm{k}_{1}$ at various $\left[\mathrm{HClO}_{4}\right]$ is tabulated in Table-3. It is observed that reaction rate increases with increase in $\left[\mathrm{HClO}_{4}\right]$ concentration. It indicates that reaction is acid catalyzed. The plot of $4+\log \mathrm{k}$ versus $2+\log \left[\mathrm{HClO}_{4}\right]$ is a linear with slope nearness to Unity shows the first order dependence of $\left[\mathrm{H}^{+}\right]$. The rate is measured in presence of benzalkonium chloride was shown in Fig. 3.

\begin{tabular}{|c|c|c|c|c|}
\hline & $\begin{array}{r}\text { EFFECT } \\
\text { PERCHLOR }\end{array}$ & $\begin{array}{l}\text { TABLE-3 } \\
\text { RATE O } \\
\text { ACID CO }\end{array}$ & $\begin{array}{l}\text { ARYIN } \\
\text { NTRA }\end{array}$ & \\
\hline & & & Benza & ium chloride \\
\hline [Substrate] & $\begin{array}{l}\text { Perchloric } \\
\text { acid }\end{array}$ & $\mathrm{NaClO}_{4}$ & $\begin{array}{c}10^{4} \mathrm{k}_{1} \\
\left(\mathrm{~s}^{-1}\right)\end{array}$ & $\begin{array}{c}10^{2} \mathrm{k}_{2} \\
\left(\mathrm{~mol}^{-1} \mathrm{dm}^{3} \mathrm{~s}^{-1}\right)\end{array}$ \\
\hline & 0.1 & 0.4 & 2.11 & 2.11 \\
\hline Lactic acid & 0.2 & 0.3 & 4.18 & 2.09 \\
\hline Lactic acid & 0.3 & 0.2 & 6.28 & 2.10 \\
\hline & 0.4 & 0.1 & 8.43 & 2.11 \\
\hline & 0.1 & 0.4 & 0.76 & 0.76 \\
\hline Mandelic & 0.2 & 0.3 & 1.50 & 0.75 \\
\hline acid & 0.3 & 0.2 & 2.26 & 0.75 \\
\hline & 0.4 & 0.1 & 3.11 & 0.78 \\
\hline & 0.1 & 0.4 & 0.85 & 0.85 \\
\hline Lactato & 0.2 & 0.3 & 1.71 & 0.85 \\
\hline complex & 0.3 & 0.2 & 2.57 & 0.86 \\
\hline & 0.4 & 0.1 & 3.43 & 0.86 \\
\hline & 0.1 & 0.4 & 0.45 & 0.45 \\
\hline Mandelato & 0.2 & 0.3 & 0.90 & 0.44 \\
\hline complex & 0.3 & 0.2 & 1.34 & 0.45 \\
\hline & 0.4 & 0.1 & 1.79 & 0.45 \\
\hline
\end{tabular}

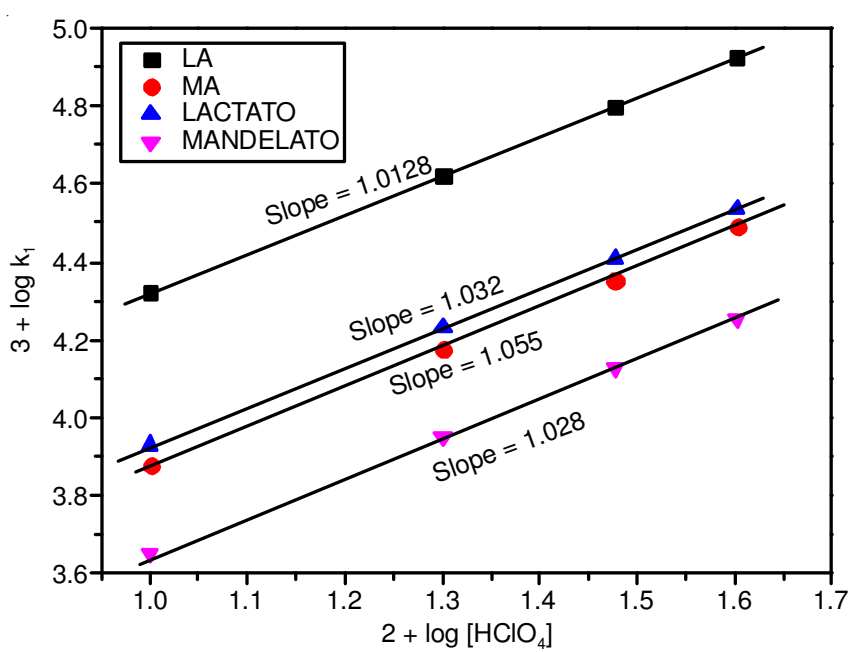

Fig. 3. Rate dependence of perchloric acid in presence of benzalkonium chloride

Comparison of rate dependence of perchloric acid is given in presence of benzalkonium chloride as follows:

Lactic acid > Lactato $>$ Mandelic acid > Mandelato

Rate dependence on ionic strength: Influence of ionic strength on the rate of oxidation of hydroxy acids by TriBACC was attempted at different concentration of sodium perchlorate at room temperature. Concentration of other reactants was the same. The data is tabulated in Table-4. From the table it materializes the absence of salt effect and the increase in the rate is only due to $\mathrm{H}^{+}$ion. This is because one of the reactants is neutral and other is positively charged.

\begin{tabular}{ccc}
\multicolumn{3}{c}{$\begin{array}{c}\text { TABLE-4 } \\
\text { EFFECT OF RATE ON VARYING IONIC STRENGTH }\end{array}$} \\
\hline $10^{3}$ [Substrate] & {$\left[\mathrm{NaClO}_{4}\right]$} & $10^{3} \mathrm{k}_{1}\left(\mathrm{~s}^{-1}\right)$ \\
\hline \multirow{3}{*}{ Lactic acid } & 0.1 & 5.61 \\
& 0.2 & 5.49 \\
& 0.3 & 5.58 \\
& 0.4 & 5.57 \\
\hline \multirow{3}{*}{ Mandelic acids } & 0.1 & 3.95 \\
& 0.2 & 3.89 \\
& 0.3 & 3.92 \\
Lactato complex & 0.4 & 3.94 \\
& 0.1 & 4.11 \\
& 0.2 & 4.15 \\
& 0.3 & 4.11 \\
Mandelato complex & 0.4 & 4.18 \\
\hline & 0.1 & 2.77 \\
& 0.2 & 2.72 \\
& 0.3 & 2.68 \\
\hline
\end{tabular}

Effect of added pyridine and picolinic acid: Pyridine and picolinic acid was added to the reaction mixture. It is observed that the conservative in rate of the reaction which concludes that TriBACC is stable in aqueous perchloric acid medium.

Dependence of rate on varying micellar concentration: On varying the concentration of benzalkonium chloride at $0.0052,0.01,0.015,0.02$ and $0.03 \mathrm{~mol} \mathrm{dm}^{-3}$ shows a progressive increase in the rate. A plot of $\log \mathrm{k}$ versus $3+\log [\mathrm{BKC}]$ gives sigmoidal curve. Comparison of rate is given below in Table-5 and Fig. 4.

\begin{tabular}{ccc}
\multicolumn{3}{c}{ TABLE-5 } \\
& \\
& EFFECT OF RATE ON VARYING & \\
MICELLAR CONCENTRATION & \\
\hline $10^{3}$ [Substrate] & Benzalkonium chloride & $10^{3} \mathrm{k}_{1}\left(\mathrm{~s}^{-1}\right)$ \\
\hline & 0.0052 & 2.14 \\
Lactic acid & 0.0100 & 4.25 \\
& 0.1500 & 4.83 \\
& 0.2000 & 5.24 \\
& 0.3000 & 5.58 \\
\hline \multirow{2}{*}{ Mandelic acids } & 0.0052 & 0.89 \\
& 0.0100 & 1.77 \\
& 0.1500 & 2.37 \\
& 0.2000 & 2.87 \\
& 0.3000 & 3.27 \\
\hline Lactato complex & 0.0052 & 0.77 \\
& 0.0100 & 1.53 \\
& 0.1500 & 2.03 \\
& 0.2000 & 2.43 \\
Mandelato complex & 0.3000 & 2.73 \\
\hline & 0.0052 & 0.85 \\
& 0.0100 & 1.72 \\
& 0.1500 & 2.33 \\
& 0.2000 & 2.82 \\
& 0.3000 & 3.51 \\
\hline
\end{tabular}




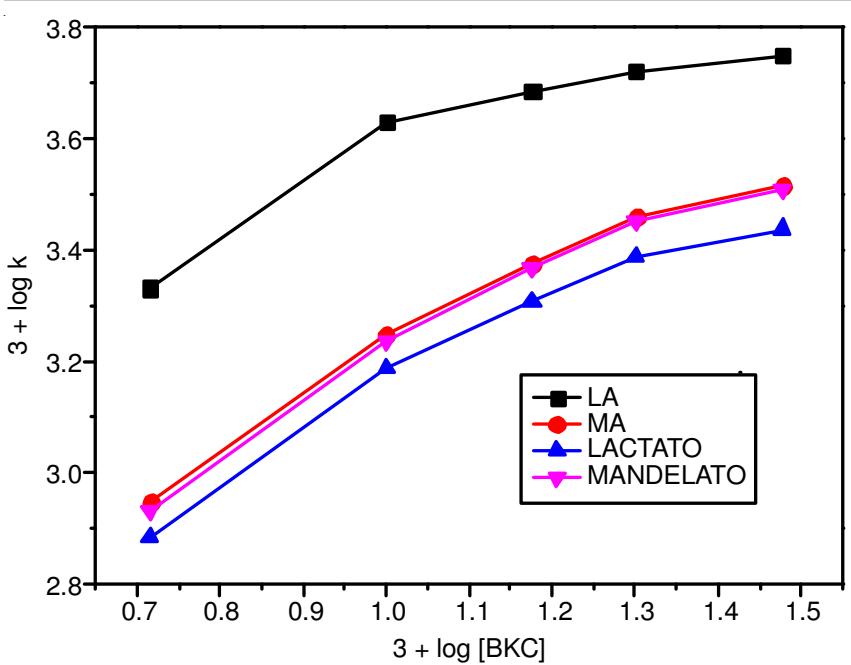

Fig. 4. Rate dependence of micellar (benzalkonium chloride) variation

Comparison of rate dependence of micellar (benzalkonium chloride) variation is given as follows:

\section{Lactic acid $>$ Mandelic acid $>$ Mandelato $>$ Lactato}

Polymerization test: Polymerization test was conducted using acrylonitrile. To the $0.1 \mathrm{M}$ substrate solution in $10 \mathrm{~mL}$ of perchloric acid, few drops of acrylonitrile was added. To this $5 \mathrm{~mL}$ of $0.01 \mathrm{M}$ of TriBACC was added and shaken well. Solution was kept under nitrogen atmosphere for $2 \mathrm{~h}$ in a thermostat. No polymer is formed shows that the absence of radical formation during the reaction.

Product analysis and stoichiometry: Product analysis was done spectrophotometrically. TriBACC $(0.9 \mathrm{M})$ and substrate $(0.3 \mathrm{M})$ were mixed together with $\mathrm{HClO}_{4}(1 \mathrm{M})$ and total volume is $100 \mathrm{~mL}$. The reaction mixture is kept for 9 half lives $(48 \mathrm{~h}$ ) for almost $80 \%$ completion of the reaction. Moles of TriBACC consumed were determined by difference in absorbance before and after completion of reaction. The solution is neutralized using saturated $\mathrm{KHCO}_{3}$ and the product. The mixture was treated with 2,4-dinitrophenyl-hydrazine. Yelloworange precipitate formed is extracted with diethyl ether is dried and weighted and hence Stoichiometry was confirmed. Benzaldehyde was formed on oxidation of mandelic acid while acetaldehyde was formed on oxidation of lactic acid. In both cases IR spectral data was agreed with the authentic samples. This estimation indicated that hydroxy acids and TriBACC was consumed in 1:0.67 mole ratio (one electron transfer) while for cobalt(III) complex it was observed in 1:0.35 mole ratio (two electron transfer). The stoichiometric equation is given as:

$$
\begin{array}{r}
\mathrm{RCH}(\mathrm{OH}) \mathrm{COOH}+\mathrm{Cr}(\mathrm{VI})+\mathrm{H}_{3} \mathrm{O}^{+} \longrightarrow \\
\mathrm{RCHO}+\mathrm{Cr}(\mathrm{V})+\mathrm{H}_{2} \mathrm{O}+\mathrm{CO}_{2}+3 \mathrm{H}^{+} \\
\mathrm{RCH}(\mathrm{OH}) \mathrm{COO}-\mathrm{Co}(\mathrm{III})+\mathrm{Cr}(\mathrm{VI})+\mathrm{H}_{3} \mathrm{O}^{+} \longrightarrow \\
\mathrm{RCHO}+\mathrm{Cr}(\mathrm{V})+\mathrm{H}_{2} \mathrm{O}+\mathrm{CO}_{2}+2 \mathrm{H}^{+}+\mathrm{Co}(\mathrm{II})
\end{array}
$$

Chromium(V) was finally converted into $\mathrm{Cr}$ (III). Cr(III) and $\mathrm{Co}$ (II) was confirmed by visible spectra after completion of the reaction. Stoichiometry data is given in Table-6.

Mechanism: On accounting the product analysis, polymerization test and stoichiometric data a suitable mechanism has been suggested. The oxidation mechanism mainly proceeds by $\alpha-\mathrm{C}-\mathrm{H}$ bond fission in slow step with the transfer of hydride ion:<smiles></smiles>

Cobalt(III) complex $\left(\mathrm{R}=\mathrm{CH}_{3}, \mathrm{C}_{6} \mathrm{H}_{5}\right)$<smiles></smiles>

TriBACC<smiles>F[C@H]1C[C@@H](F)C1</smiles>

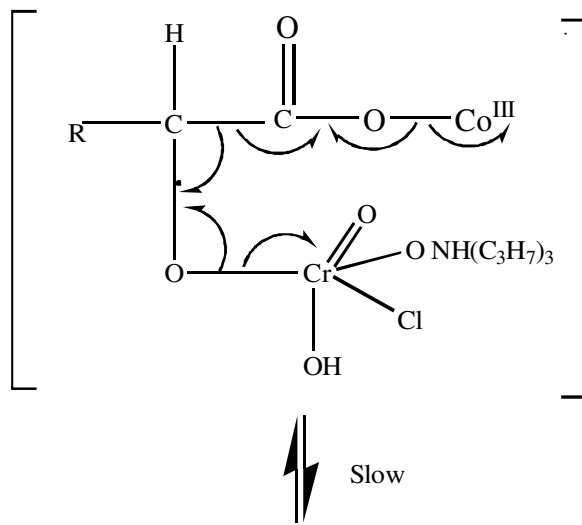

Intermediate assumed<smiles>[R]C(=O)[C-]=C[O+]=O</smiles>

TABLE-6

STOICHIOMETRIC DATA FOR TriBACC OXIDATION OF CO(III) BOTH BOUND AND UNBOUND $\alpha$-HYDROXY ACIDS IN THE PRESENCE OF BENZALKONIUM CHLORIDE

\begin{tabular}{ccccc}
\hline $\begin{array}{c}10^{3}[\text { Compound }] \\
\left(\mathrm{mol} \mathrm{dm}^{-3}\right)\end{array}$ & $\begin{array}{c}10^{2}[\mathrm{TriBACC}]_{\text {initial }} \\
\left(\mathrm{mol} \mathrm{dm}^{-3}\right)\end{array}$ & $\begin{array}{c}10^{2}\left[\mathrm{TriBACC}_{\text {final }}\right. \\
\left(\mathrm{mol} \mathrm{dm}^{-3}\right)\end{array}$ & $\begin{array}{c}10^{3} \Delta[\text { TriBACC }] \\
\left(\mathrm{mol} \mathrm{dm}^{-3}\right)\end{array}$ & {$[$ Compound $]: \Delta[$ TriBACC $]$} \\
\hline $\begin{array}{c}\text { Mandelic acid } \\
2.0\end{array}$ & 2.0 & 1.870 & 1.33 & $1.00: 0.66$ \\
4.0 & 2.0 & 1.730 & 2.68 & $1.00: 0.67$ \\
$\begin{array}{c}\text { Lactic acid } \\
2.0\end{array}$ & 2.0 & 1.868 & 1.32 & $1.00: 0.66$ \\
4.0 & 2.0 & 1.740 & 2.60 & $1.00: 0.65$ \\
Lactato & 2.0 & & & 1.40 \\
4.0 & 3.0 & 1.86 & 2.20 & $1.00: 0.35$ \\
6.0 & & 2.78 & & $1.00: 0.37$ \\
Mandelato & 2.0 & 1.85 & 1.50 & $1.00: 0.38$ \\
4.0 & 3.0 & 2.82 & 1.80 & $1.00: 0.36$ \\
5.0 & & & \\
\hline
\end{tabular}




\section{Conclusion}

The hydroxy acids bound and unbound oxidation by new reagent TriBACC has been investigated in perchloric acid medium at room temperature. The oxidation of hydroxy acids is first order with respect to each TriBACC, perchloric acid. This oxidation is catalyzed by cationic benzalkonium chloride. On varying the concentration of substrate, perchloric acid shows a progressive increase in the reaction rate with slope is near to unity. Variation of micellar concentration shows a progress of increase in the rate and a plot gives sigmoidal curve. Polymerization test shows no intermediate is formed during the course of the reaction. Product formed benzaldehyde, acetaldehyde were analyzed. Stoichiometry data shows that hydroxy acids and TriBACC was consumed in 1:0.67 mole ratio (one electron transfer) while for cobalt(III) complex it was observed in 1:0.35 mole ratio (two electron transfer). A suitable mechanism has been given.

\section{ACKNOWLEDGEMENTS}

The authors thank Dr. Ramaraj, Madurai Kamaraj University, Madurai, India and Dr. P. Rajkumar, Department of Chemistry, Priyadharshini Engineering College, Vaniyambadi, India for valuable suggessions .

\section{REFERENCES}

1. $\quad$ S. Patel and B.K. Mishra, Tetrahedron, 63, 4367 (2007); https://doi.org/10.1016/j.tet.2007.02.073.

2. S. Srivastava and P. Srivastava, J. Saudi Chem. Soc., 13, 247 (2009); https://doi.org/10.1016/j.jscs.2009.10.003.
3. B.M. Nawaz and K. Subramani, Int. J. Chem. Sci, 8, 2438 (2010).

4. S. Shanthi and S.S. Mansoor, Chem. Sci. Trans., 4, 213 (2015); https://doi.org/10.7598/cst2015.974

5. B.L. Hiran, J. Khuntwal, R.K. Malkani and D. Singh, Arab. J. Chem., 9 Suppl. 1, S440 (2011); https://doi.org/10.1016/i.arabjc.2011.05.017.

6. J. Dharmaraja, K. Krishnasamy and M. Shanmugam, Int. J. Frontiers Sci. Technol., 5, 754 (2008).

7. P. Swami, D. Yajurvedi, P. Mishra and P.K. Sharma, Int. J. Chem. Kinet., 42, 50 (2010); https://doi.org/10.1002/kin.20466.

8. S. Ghammamy and M. Mazareey, J. Serb. Chem. Soc., 70, 687 (2005); https://doi.org/10.2298/JSC0505687G.

9. E.S. Gould, H. Taube, J. Am. Chem. Soc., 86, 1318 (1964); https://doi.org/10.1021/ja01061a012.

10. M.A. Malik, F.M. Al-Nowaiser, N. Ahmad and Z. Khan, Int. J. Chem. Kinet., 42, 704 (2010); https://doi.org/10.1002/kin.20519.

11. V.S. Malik, I. Vannamuthu, S.S. Shaffi and S.S. Mansoor, Chem. Sci. Trans., 4, 523 (2015); https://doi.org/10.7598/cst2015.994.

12. S.S. Mansoor, V.S. Malik, K. Aswin, K. Logaiya and A.M. Hussain, J. Saudi Chem. Soc., 20 Suppl. 1, s77 (2016); https://doi.org/10.1016/j.jscs.2012.09.013.

13. K. Mahanpour, S. Ghammamy and R. Rahimi, Asian J. Chem., 21, 4404 (2009).

14. S.A. Chimatadar, M.S. Salunke and S.T. Nandibewoor, Indian J. Chem., 45A, 388 (2006).

15. D.S. Dhage, D.R. Munde and S.P. Pachling, Int. J. Chem. Sci., 7, 423 (2009).

16. S. Agarwal and A.V. Sharma, Int. J. Chem. Sci., 10, 1735 (2012).

17. L. Kotai, P.K. Sharma, N. Malani and P. Panchariya, Int. J. Chem. Sci., 10, 557 (2012).

18. N. Prabhu and B.M. Nawaz, Int. J. Chem. Sci., 9, 872 (2011). 